\title{
Bayamo la ciudad incendiada en Cuba colonial. Condiciones de vida durante la diáspora poblacional entre 1869-1879
}

\section{Bayamo the city burned down in colonial Cuba. Living conditions during the population diaspora among 1869-1879}

\author{
Diurkis Yarenis Madrigal León \\ Universidad de Granma, Cuba \\ dmadrigall@udg.co.cu
}

\begin{abstract}
Resumen
El presente artículo es el resultado de una investigación de corte socio histórica que indaga en los acontecimientos ocurridos después de la quema provocada el 12 de enero de 1869 en la ciudad de Bayamo, territorio donde se iniciaron y acrisolaron las ideas independentistas contra el dominio español.

El objetivo consiste en develar las condiciones de vida experimentadas por los moradores de Bayamo durante la diáspora poblacional entre 1869 y 1879, después de concretarse la quema de la ciudad. Para la indagación científica se implementó un profundo trabajo con documentos propios del período, además de la indagación detallada desde fuentes de transmisión oral.

Posterior a la quema de la ciudad, la población se dispersó, desde entonces se estructuró y consolidó un proceso de emigración poblacional hacia diferentes zonas del oriente de Cuba y países cercanos. La metrópoli española incrementó severas formas de represión revestidas de asesinatos y crímenes, fundamentalmente contra las familias de los patriotas que iniciaron la guerra y el resto de los habitantes que continuaron el tránsito por las serranías. La ciudad se caracterizó por un perenne estado de ruinas y la población por un severo desgarramiento emocional que resultó patente durante las tres últimas décadas del período colonial.
\end{abstract}

Palabras clave

Incendio; ciudad de Bayamo; diáspora; familias; represión.

\begin{abstract}
This article is the result of a socio-historical investigation, which investigates the events that occurred after the burning that occurred on January 12, 1869 in Bayamo, where the independence ideas against Spanish rule were initiated and refined. The objective is to reveal the living conditions experienced by the residents of Bayamo during the population diaspora, after the burning of the city took place. For the scientific investigation, a deep work it was implemented with documents of the period, in addition to Esta obra está sujeta a la Licencia Reconocimiento-NoComercial-CompartirIgual 4.0 Internacional de Creative Commons. http://creativecommons.org/licenses/by-nc-sa/4.0/




\section{Diurkis Yarenis Madrigal León}

the detailed research of other sources with emphasis on the oral tradition. The facts reveal that after the burning, a process of population migration to different areas of eastern Cuba and nearby countries was structured and consolidated. The testimonies reveal the forms of repression implemented by the metropolis as mechanisms of subjection, covered with murders and crimes, fundamentally against the families of the patriots who initiated the war and the rest of the inhabitants who continued the transit through the mountainous areas. The city was characterized by a perennial state of ruins and the population by a severe emotional tear that was evident during the last three decades of the colony.

Keywords: fire; city of Bayamo; diaspora; families, repression.

\section{Introducción}

Bayamo $^{1}$ fue la segunda Villa de la isla de Cuba fundada en 1513, cuya historia tiene raíces muy antiguas. Los bayameses viven orgullosos de su historia, fundamentalmente aquella que permitió conocer y elevar el nombre patriótico de la ciudad $^{2}$, la tierra del Himno Nacional, del mérito insigne por iniciar la Primera Guerra de Liberación Nacional y ser partícipes de las ideas que acrisolaron y matizaron el carácter patrio de la nacionalidad cubana.

La gesta independentista se ha convertido en objeto de estudio para la ciencia historiográfica nacional regional y local; concretamente las investigaciones se han concentrado en estudiar el altruismo de los próceres de la independencia que lideraron la guerra patriótica y el simbolismo que posee este hecho para la historia del país. Sin embargo, ha quedado en un espacio desierto el protagonismo ejercido por las personas que residían en el territorio, quienes sacrificaron el bienestar del hogar como expresión de patriotismo. Al decir del historiador Enrique Orlando Lacalle: "aquí se inmoló un pueblo y de sus ruinas calcinadas surgió la patria cubana $^{3 "}$

Se trata de una parte de la historia poco privilegiada en la trayectoria regional y nacional y que por su trascendencia precisan de mayor rigor investigativo, máxime cuando se desconocen los significativos posicionamientos que involucran hechos y acontecimientos de la localidad y sin embargo, han sido ignorados o simplemente inadvertidos por la historiografía regional.

En ese sentido, conviene indagar en la historia que no ha sido fundamentada con precisión, específicamente resultan de interés las vivencias y testimonios de aquellas tantas personas que después de la quema de la ciudad resultaron protagonistas anónimos en los escenarios de batalla, y en cambio prefirieron morir

\footnotetext{
${ }^{1}$ El nombre de Bayamo tiene dos orígenes posibles: una tendencia apunta a que cogió el calificativo del nombre del Cacique que lideraba en la zona, y la otra indica la existencia del, árbol Bayam, importante por su sabiduría, frondoso y de buena sombra.

${ }^{2}$ La declaración de Bayamo con el título de ciudad acontece en el año 1836

${ }^{3}$ Lacalle y Zauquest E. O. 2010. Cuatro siglos de historia de Bayamo. Proyecto Memoria. Bayamo. Ediciones Bayamo
} 


\section{Bayamo la ciudad incendiada en Cuba colonial. Condiciones de vida durante la diáspora poblacional entre 1869-1879}

en condiciones escalofriantes; unos alejados de sus hogares y otros separados de riquezas, bienes y comodidades.

Varias preguntas causan motivación: ¿hacia dónde se dirigieron después del incendio?, ¿cómo sobrevivieron tantas personas que avanzaron sin rumbo?; ¿Cuál fue el destino de aquellos que estuvieron involucrados en la gesta independentista?

La investigación devela los acontecimientos acontecidos en el Bayamo Insurrecto, en un periodo donde se recrudecen las medidas por parte de la política española sobre todos los órdenes del sistema de vida social, y fundamentalmente sobre la población que emigró atravesando las más crueles penurias por los campos del oriente de Cuba, como parte de la gran diáspora histórica después de la quema gloriosa de la ciudad.

Hoy la historia se compromete en develar una realidad difícil de construir, en tanto, no existen narraciones completas sobre lo acontecido en esos años, principalmente respecto a las condiciones de vida afrontadas por la población que salió en masa de la ciudad. Precisamente en ello versa la trascendencia del presente estudio, en la medida que se exponen nuevos conocimientos que resultaban enigmas para la historiografía regional y donde obviamente su reconstrucción implica un análisis cuidadoso que involucra el uso de diversas fuentes documentales y testimoniales.

Para este caso se tuvo en cuenta la inclusión cuidadosa de protocolos notariales, documentos del Fondo del Gobierno Municipal Colonia, actas de matrimonios y nacimientos, censos del siglo XIX, padrones locales. Para complementar las narraciones fue imprescindible la revisión de escritos periodísticos de la época, diarios de campaña, además de la consulta de cartas familiares, canciones y poemarios, incluso la importancia de las entrevistas a descendientes de familias que vivieron en el período, las cuales intervienen como fuentes significativas de transmisión oral.

El estudio de esta etapa es trascendental para comprender la repercusión de los cambios estructurales, políticos y económicos en la sociedad bayamesa de entonces, además de su incidencia en la conformación de una definitiva conciencia emancipatoria y la maduración de un pensamiento antimperialista radical.

\section{Bayamo antes de la quema. Situación socioeconómica y posicionamiento de su gente}

Desde la fundación de las primeras villas, la isla de Cuba fue valorada como un territorio único, hasta que por Real Decreto, en 1607, se dividió en dos provincias, Oriental y Occidental. En 1827 se decretó la nueva división en tres departamentos occidental, central y oriental y ésta a su vez en términos municipales. Particularmente la jurisdicción de Bayamo en 1513 ocupó algunos territorios de las actuales provincias de Tunas, Holguín, Granma y Santiago de Cuba; más tarde, hacia el año 1774 el padrón indica una nueva delimitación territorial que corresponden a 


\section{Diurkis Yarenis Madrigal León}

la actual provincia de Granma4. Bayamo llegó a ser centro del poder político de la isla, donde radicaban las fundiciones de oro y punto de abastecimiento de vital importancia para garantizar la conquista de tierra firme.

En la vida económica de Bayamo la ganadería ocupó un lugar preponderante durante los siglos XVI y el XVII, ello hizo posible el desarrollo del latifundio ganadero y posteriormente de las haciendas comuneras. Al unísono se fomentaba el cultivo del azúcar, aunque a ritmo lento. De igual modo ocupó un lugar importante el comercio de rescate y contrabando ${ }^{5}$. El siglo XVIII y la primera mitad del siglo XIX transcurre con mayor auge económico y cultural. En este período se destacan insignes oradores, poetas, músicos y escritores que plasmaron un significativo legado a la cultura nacional6, incluso muchos de ellos contribuyeron de forma notable en el desarrollo de la cultura en países de América ${ }^{7}$. Esta época ha sido considerada como fecunda en la vida socioeconómica arquitectónica y cultural de Bayamo ${ }^{8}$, de ahí la denominación como "Siglo de Oro bayamés".

\section{Las razones para la quema de la ciudad: antecedentes y argumentos}

A finales del año 1868, la ciudad de Bayamo, se había convertido en capital de la República en Armas, se anunciaba como símbolo de la independencia cubana, en tanto, se habían germinado y desarrollado las ideas conspirativas que dieron inicio $^{9}$ a la guerra contra el régimen español. Bayamo se había convertido en una amenaza para la estabilidad y el orden hegemónico de España en la isla de Cuba.

Tales premisas condicionaron el advenimiento de una intensa represalia militar por parte de la metrópoli, España había decidido acabar con las influencias independentistas del Bayamo rebelde. Para impedir la entrada de las tropas españolas y evitar el sometimiento colonial, los líderes bayameses tuvieron una alternativa: "la quema de la ciudad por sus propios habitantes el 12 de enero de 1869".

\footnotetext{
${ }^{4}$ Lago Vieito Ángel: Bayamo en el Crisol de la Nacionalidad Cubana. p.10 Con respecto a éstos límites el autor señala su carácter aproximado de acuerdo con la observación del mapa confeccionado por José M. de la Torre en 1841

${ }^{5}$ El comercio de contrabando estaba tan generalizado en la población bayamesa que se decía que hasta los negros practicaban el contrabando. Entre los artículos para el comercio figuraban: cueros, quesos y otros derivados del ganado. El comercio fue activo con países europeos, ingleses, holandeses y principalmente con Francia.

${ }^{6}$ Bayamo fue el territorio donde sucedieron los hechos narrados en la primera obra literaria cubana, "Espejo de Paciencia"; se escribió y cantó la primera canción romántica de Cuba, "La bayamesa". Cuna natal de poetas y escritores de la talla de Juan Clemente Zenea, José Antonio Saco, José Fornaris, José Joaquín Palma, Tristán de Jesús Medina, entre otros.

7 Es el caso del bayamés José Joaquín Palma Lasso. Fue poeta, profesor, diplomático y periodista. Escribió la letra del Himno Nacional de Guatemala.

${ }^{8}$ La pérdida de una gran parte de fuentes documentales por causa del fuego; ha impedido mostrar datos y detalles importantes sobre la vida en la ciudad antes de producirse la quema.

9 Meses antes del incendio, el 10 de octubre de1868, el bayamés Carlos Manuel de Céspedes, conocido como "Padre de la Patria", inició el movimiento independentista que decretó el camino independentista en Cuba.
} 


\title{
Bayamo la ciudad incendiada en Cuba colonial. Condiciones de vida durante la diáspora poblacional entre 1869-1879
}

\section{El incendio. La diáspora ${ }^{10}$ familiar y el curso palpable de la tortura y la muerte}

La historia relata que la ciudad fue presa de las llamas por varios días. La obra Anales de la guerra de Cuba, de Antonio Pirala, recoge el siguiente testimonio de un soldado español:

Aun habían algunas casas que eran presa de las llamas; en cambio la mayor parte ofrecían tan solo las cenizas aun calientes del incendio o los ruinosos escombros del desplome.

Seguimos avanzando lentamente, un silencio sepulcral cerraba los labios de todo el mundo, todos pensábamos, contemplábamos las puertas de las casas en el suelo [...] ¿Qué se habrá hecho nos decíamos unos a otros, de las dos mil familias que habitaban este pueblo? ¿A donde están los enfermos, los ancianos y los niños? Horror causa la respuesta [...] $]^{11}$

Más de tres días ardió la ciudad, se desplomaron casas, muros, establecimientos, se deterioraron plazas y calles que alargaban la permanencia de una atmosfera irrespirable. Así declara el bayamés Juan Jerez Villarreal ${ }^{12}$ :

\begin{abstract}
Aplican la tea devastadora a las casas del Zaguán propio donde nacieron (...) Los templos de altares lujosos (...) son pasto del incendio; los almacenes del próspero comercio, las tiendas de ropas, las farmacias, las sociedades, las escuelas tórnase ascua viva.

Abajo, tiznados los rostros aplopégicos y sudorosos, heridos los brazos y manos, la legión destructora prosigue embriagada por el genio del exterminio, la terrible faena de acabar de una vez.

Todavía sienten las frentes altivas, en el pulso que no tembló (...) pero no vuelven las caras (...) sonríen (...) la voz de mando metálica y dura grita ;A paso largo! Y como tropel fantástico de centauros, se pierden en las tinieblas que avanza.

Los que salieron el nueve y el diez, los que durmieron sus pesadillas al desamparo de la noche, tirados en la húmeda esterilla del espartillal, los que tuvieron por almohada la raíz saliente de un árbol amigo, entumecidos aún por el frío mañanero, contemplan la lejana fragua llameante donde acaso se esté forjando la Patria Nueva. Para ellos, de la que fue prez y orgullo, sólo resta, en el horizonte mudo, un resplandor rojizo ${ }^{13}$.
\end{abstract}

En el primer mes del nuevo año, la ciudad de Bayamo avizoraba el comienzo de un largo período de abatimiento progresivo. La destrucción era palpable en todos los ámbitos de la vida económico social, decae la producción comercial, y agropecuaria, la instrucción educacional y sanitaria, desaparece la fuerza artístico cultural e intelectual del territorio.

\footnotetext{
10 Toda la población se dispersó por la imposibilidad de sobrevivir frente a las llamas y el posterior asedio por parte de las autoridades españolas.

11 Pirala, Antonio, Anales de la guerra de Cuba, (S.E.), Madrid, 1896, p. 393.

12 Juan Jerez Villarreal: Escritor y periodista, nacido en Bayamo, Cuba el 18 de julio de 1890

13 Jerez Villarreal, Juan, Gesta de Bravos. Episodios inéditos de la Revolución de 1968, Talleres tipográficos de cuba intelectual, La Habana, 1926, pp. 34-37.
} 


\section{Diurkis Yarenis Madrigal León}

El desplazamiento poblacional inicia dos o tres días antes de producirse el incendio, principalmente comenzaron a salir de la ciudad los comerciantes que veían amenazados sus bienes y la tranquilidad de sus negocios. En declaraciones de algunos comerciantes al gobierno de la ciudad consta:

Siete días antes de la invasión salieron para Santiago los comerciantes Don Jaime Hill y Don Antonio Tasis a manifestar al comandante los peligros que los amenazaban, los tres meses de Revolución se transformaron en un martirio, no podían hablar contra la Revolución del mambí14.

Con un tiempo prudencial, también salieron las familias de los principales líderes que condujeron el estallido de la Revolución y la gran masa de estratos humildes (esclavos, negros y mulatos libres, campesinos, hombres de oficio) con la firme posición de acatar el refugio del monte y la solidaridad de campesinos cercanos. Una de las narraciones recogidas durante la campaña contempla:

Se trasladó a un lugar seguro a los ancianos e inválidos y prestar ayuda en su retirada a mujeres y niños, gritos y lamentaciones por todas partes unos maldiciendo a los españoles y otros censurando a los patriotas por no impedir la aproximación enemiga ${ }^{15}$.

Otra parte de los propietarios que se quedaron hasta el último momento de estallar el fuego, se desplazaron hasta las proximidades más seguras en las afueras de la ciudad. Así relatan Don José y Vicente Más: "No pudiendo salvar nada tuvimos que salir precipitadamente para ocultarnos en las montañas con la familia compuesta por doce personas"16.

\section{La diáspora}

La ciudad quedó desierta, la tenacidad del fuego había dado un vuelco contundente al espíritu de vida anterior, tras la pérdida de sus propiedades, casas comerciales, panaderías, ferreterías, ganados, cultivos se vieron obligados a emigrar de la ciudad. Sobre el incidente apuntan: "En el estado de ruinas en que ha quedado la población, todos los peninsulares que allí habitamos, tenemos que emigrar forzosamente, para buscar en otra parte los medios de satisfacer nuestras primeras necesidades"17.

Desde ese momento comienza una etapa denominada diáspora poblacional, donde la dispersión adquirió matices elevados. Comienza un período de movilidad geográfica y social, la cual estuvo generada por un proceso de emigración en círculos expandidos hacia zonas rurales, montañosas e incluso el exilio como forma más segura para la población. El exilio tomó el matiz de medida gubernamental que

\footnotetext{
14 (CNC) Casa de la Nacionalidad Cubana, Sala de Información, Fondo Colonia, Reclamación de posesiones, Documento inédito, p.1.

15 Izaguirre, José María, Recuerdo de la Guerra de los Diez Años, (S.E.), (S.L.), (S.A.), p.19.

16 (CNC) Casa de la Nacionalidad Cubana, Ob.Cit., p.2.

17 (CNC) Casa de la Nacionalidad Cubana, Ob.Cit., p.3.
} 


\section{Bayamo la ciudad incendiada en Cuba colonial. Condiciones de vida durante la diáspora poblacional entre 1869-1879}

significaba el destierro, confinamiento y expatriación de cada persona confinada como traición al gobierno español.

En tales circunstancias se agudizaron las represalias contra la población civil a partir de la política represiva del gobierno español, revestida de persecución, crímenes y asesinatos contra familias enteras, sin concesiones de clase, edad o sexo. Entre los años 1869 y 1871 los bayameses afrontaron en los montes las más grandes miserias: “(...) casados como lobos huían a los distritos más salvajes buscando refugio en los bosques más espesos (...)"18.

Las leyes y disposiciones de la nueva jefatura colonial influyeron en el proceso extensivo de movilidad geográfica y social. Si bien la emigración se tornó efectiva hacia los campos más cercanos, paulatinamente se fue extendiendo hacia zonas montañosas e incluso hacia lugares inhóspitos, inhabitables e inaccesibles, al convertirse en espacios inseguros tras la persecución del cuerpo de voluntarios al servicio del gobierno español. De ahí que ese movimiento alcance matices progresivos desde la ciudad hasta el campo, las serranías y finalmente el exilio. Ese proceso de emigración se mantuvo con mayor fuerza entre los primeros cinco años de la guerra, pero nunca se detuvo.

Las familias acogidas al exilio también afrontaron momentos agobiantes. Las leyes coloniales habían decretado a partir de octubre de 1871 la salida de la Isla en el término de diez días a todas aquellas personas comprendidas entre las viejas y patrióticas familias ${ }^{19}$ de la ciudad. La estipulación condicionó la emigración hacia el extranjero de las familias de los principales dirigentes de la Revolución para exiliarse en EE.UU., México, Panamá, Colombia, Costa Rica, Guatemala y fundamentalmente en Jamaica. Es el caso de las familias: Carlos Manuel de Céspedes, denominado por todos los cubanos como "Padre de la Patria", a quien pertenece el evento glorioso de iniciar las luchas por la independencia de Cuba; Pedro Felipe Figueredo y Cisneros (Perucho) autor del Himno Nacional de Bayamo, actualmente Himno Nacional de Cuba; Francisco Vicente Aguilera y Tamayo, patriota bayamés que encabezó el primer Comité Revolucionario Cubano.

La fuerza de las disposiciones coloniales se arraigaron con pujanza hacia las familias de los patriotas que iniciaron la guerra; Francisco Vicente Aguilera ${ }^{20}$ fue uno de los próceres que marcó una página importante en la historia de Cuba. Para Aguilera el costo de la libertad implicó la renuncia y el abandono voluntario de sus bienes. Generalmente actitudes como estas resultan incomprensibles para quienes no abrazan la patria como parte intrínseca del propio ser.

¿Qué sentido tenía desechar, desistir y separarse de la riqueza, la opulencia y el bienestar familiar? ¿Por qué la virtud de abrazar la adversidad, las privaciones y

18 OKelly James, La Tierra del Mambí, Instituto del Libro, Habana, 1968, p. 17.

19 Familias enteras eran partícipes de las ideas conspirativas contra el dominio español. De ahí su trascendencia patriótica, en tanto, estaban convencidos de la necesidad de la lucha armada para lograr la independencia de Cuba.

20 Francisco Vicente Aguilera y Tamayo: patriota bayamés que encabezó el primer Comité Revolucionario Cubano en las luchas por la independencia de Cuba. 


\section{Diurkis Yarenis Madrigal León}

las angustias de los días sin límites, ni fecha para la paz? Aguilera sabía las implicaciones de sus palabras: "Todo está perdido para mí, mientras no tenga patria. Los españoles están ahí se apoderaran de Bayamo y de sus bienes, y nosotros no podremos defenderlos; yo renuncio a los míos"21

En las cartas familiares de Francisco V. Aguilera se narran elementos importantes del proceso de partida después de producirse el incendio de la ciudad. En una carta, una de sus hijas comenta: "En Manzanillo22 están botando a todos los cubanos residentes allí, aquí han venido cuatro goletas cargadas, en fin esta todo Bayamo [...] dicen que todos los días hay fuego en esa Villa"23.

La familia de Aguilera soportó implacables persecuciones por los campos orientales, aproximadamente estuvieron tres años atravesando los montes, descalzos y hambrientos, perseguidos y acosados como bestias; parecería una alucinación asumir que los anteriores tiempos de pulcritud y riqueza se transformaran en tribulaciones y tormentos. ${ }^{24}$ En Kingston Jamaica, soportaron depauperantes condiciones de vida; los niños más pequeños fueron enviados a instituciones de caridad 25 . Las hijas mayores Anitica, Leonita y Magdalena, se dedicaron a preparar dulces además del desempeño en el oficio de la costura a cambio de un pequeño saldo monetario que jamás fue suficiente, ni con el incremento de la remesa irregular enviada por parientes maternos desde Santiago de Cuba.

Aguilera conocía de las limitaciones que enfrentaba su familia en la más sumida miseria. En una de las cartas a su esposa Ana Kindelán comentó: "Me ha entristecido mucho la noticia [...] las escaseces que estaban pasando, sobre todo cuando no puedo mandarte nada porque nada tengo"26.

De modo profético estaban vigentes aquellas palabras que recalcó cuando se le comentó sobre el sacrificio de la guerra: "nada tengo mientras no tenga patria"27. Una vez lo mejor de la ética del pensamiento emancipador cubano salía a relucir. El desinterés y el desprendimiento humano son consustanciales al ideario del patriota, y son esos los valores que inculca a sus hijos. En sus cartas siempre recalcaba:

"Acepten este sacrificio no con resignación, sino con orgullo porque cuando se trata de la patria todos los sacrificios son pequeños. Ustedes tienen que dar el ejemplo de laboriosidad constante. Cuando tenga el gusto de abrazarlas me enorgulleceré" 28

\footnotetext{
21 Céspedes Argote, Onoria, Cartas familiares de Francisco Vicente Aguilera, Ediciones Bayamo, Bayamo, 1991, p.8.

22 Manzanillo: Actualmente segunda ciudad importante en la provincia de Granma

23 Céspedes, Onoria, 1991, Ob.Cit., p. 16.

24 Céspedes, Onoria, 1991, Ob.Cit., p. 9.

25 Aguilera Rojas, Eladio, Francisco Vicente Aguilera y la Revolución de Cuba de 1868, La Moderna Poesía, La Habana, 1909, p.60.

26 Céspedes, Onoria, 1991, Ob.Cit., p. 21.

27 Céspedes, Onoria, 1991, Ob.Cit., p. 5.

28 Céspedes, Onoria, 1991, Ob.Cit., p.13.
} 


\section{Bayamo la ciudad incendiada en Cuba colonial. Condiciones de vida durante la diáspora poblacional entre 1869-1879}

Si resultó cuantiosa la pérdida de tantos millones, balanceados en incalculables dotaciones de esclavos, ingenios y extensiones de tierra expandidos por toda la llanura del Cauto, ¿qué significado tendría la exposición de la familia, primero ante la guerra, el exilio y la pobreza después? La posición vertical ante la defensa de la libertad, implicó para el patriota posturas difíciles.

Entre tantas vicisitudes, ocupaban menor escala la exposición a la muerte, el embargo de sus bienes y la abstención a las comodidades y propiedades ampliamente reconocidas en toda la región oriental. Difícil resultó la decisión de separarse de los seres más queridos, a pesar del alto sentido de responsabilidad familiar. Esa acción se convirtió en la prueba más aguda de quebranto y aflicción. Al decir de su hijo Eladio Aguilera: "Tenía una espina que laceraba su alma, el pensamiento en su numerosa familia, a quien iba a abandonar en país extranjero, sin recursos, sumida en la miseria, sin otro amparo que la Providencia Divina"29.

De forma paulatina otras familias de los patriotas de la guerra decidieron incorporarse al exilio, se presentaban en el camino sosteniendo una banderilla blanca y ante el grito de ¡quién vive j debían de responder con un esfuerzo doloroso ¡España! En una de las cartas familiares de F.V. Aguilera, se corrobora el acto cargado de tan enorme sacrificio, cuando se produce el viaje desde el campo insurrecto hasta el pueblo de Manzanillo:

Por el camino cerca de un campamento nos dijeron ;Quien vive! Y otras familias que se habían reunido con nosotros en el camino dijeron ;España! eran los de Pancho Estrada. Ellos tienen la costumbre de dejar muchos días en sus campamentos a las familias presentadas ${ }^{30}$.

La familia de Perucho Figueredo ${ }^{31}$ enfrentó similares condiciones de penuria. Calculada por más de veinte personas incluyendo a los criados y su antigua servidumbre atravesó los campos de Tunas y de la región oriental de Camagüey, en condiciones nómadas y semisalvaje de vida, castigados por el sol, la sed y el hambre, alarmados, perseguidos todo el tiempo hasta el día de su captura, de la cual escaparon sus hijos Candelaria, Luz y el pequeño Ángel ${ }^{32}$. La familia de Máximo Gómez Báez ${ }^{33}$ afrontó un destino parecido. En su diario de campaña comenta:

Las familias están sufriendo de una manera terrible y es muy difícil poder atender a su seguridad y subsistencia, al fin tendré que hacer el sacrificio más doloroso de hacerla presentar a los españoles - para que así, aunque allá (Jamaica) se vea acosada de miseria- por lo menos con menos sobresalto" 34 .

${ }^{29}$ Aguilera Rojas, Eladio, 1909, Ob.Cit., p.60.

30 Céspedes, Onoria, 1991, Ob.Cit., p. 15.

31 Pedro Felipe Figueredo y Cisneros: bayamés independentista cubano, autor del Himno Nacional de Bayamo, actualmente Himno Nacional de Cuba.

32 Figueredo y Cisneros, Pedro, Discursos, Imprenta El Siglo XX, República del Brasil, 1924, p. 86.

33 Máximo Gómez Báez: estratega militar que participó y compartió la dirección en las Guerras de Independencia en $\mathrm{Cuba}$, durante la etapa colonial.

34 Gómez Báez Máximo, Diario de Campaña, Instituto del libro, La Habana, 1968, p. 5. 


\title{
Diurkis Yarenis Madrigal León
}

Semejantes condiciones relata Jorge Carlos Milanés ${ }^{35}$ en su diario de campaña: "Embarco para Jamaica mi mujer y mis hijos, sufriendo las miserias y la amargura de la emigración cubana"36.

El número elevado de familias que llegaron a Jamaica, hizo posible estrechar viejas relaciones entre parientes y conocidos; no obstante, la situación miserable que muchas de ellas tuvieron que afrontar también fue considerable. Sobre la pobreza que atravesaban las familias en Jamaica, escribe una de las hijas de Aguilera:

\begin{abstract}
Si este pueblo no fuera tan pobre lo hubiéramos ido a ver, ya que a usted le ha sido imposible venir, trabajaríamos hasta reunir el pasaje, pero no hay absolutamente en que ganar dinero; la mayor parte de la emigración cubana está en el último estado de miseria, sosteniéndose con cinco o seis chelines semanales que le pasa la beneficencia. Los cubanos que cuentan con algunos recursos ya se están marchando, en el mes pasado solamente salieron treinta y cuatro familias ${ }^{37}$.
\end{abstract}

De acuerdo con la tradición oral de la familia Tamayo Saco, sus antepasados no escaparon a la agobiante situación de esa etapa. Una de sus descendientes relata:

\begin{abstract}
Cuando se produce el incendio, mi familia se asienta en la Sierra Maestra, hacia la zona de Bueycito, donde son hechos prisioneros, más tarde logran negociar su huida hacia Colombia. Cuando deciden retornar a Bayamo después del Pacto del Zanjón, el señor Francisco Esteban

Tamayo González Ferraguer, quien fuera Fiscal de la República de Cuba en Armas, se mantuvo en un periodo de demencia temporal, producto al desastre que presenció en la ciudad 38 .
\end{abstract}

El exilio constituyó uno de los factores para la separación entre los miembros de las familias, se distanciaron hijos y padres, esposos y esposas, madres e hijos, hermanos y hermanas; lógicamente, los hombres habían quedado en el campo de batalla. Se desarrolló en Jamaica una comunidad de emigrados que no cesó hasta finales de la guerra. Kingston fue un lugar seguro para evitar las consecuencias de la guerra, pero no contra el hambre y la miseria, solo aquellos que conseguían algunos recursos lograron el traslado hacia otros destinos. De tal magnitud era el grado de penuria que el Comité de

Beneficencia para Inmigrantes Cubanos, ofrecía semanalmente a las familias entre 5 o 6 chelines para cubrir parte de la subsistencia.

\section{La presencia palpable de la tortura y la muerte}

35 Jorge Carlos Milanés: patriota bayamés que formó parte del proceso independentista contra el colonialismo español.

36 Milanés Jorge Carlos, Diario de Guerra, (CNC) Casa de la Nacionalidad Cubana, Documento Inédito. p. 18.

37 Céspedes, Onoria, 1991, Ob.Cit., p. 15.

38 Entrevista realizada a descendientes de la familia Tamayo Saco, ubicados en el árbol genealógico de Francisco V. Aguilera. 


\section{Bayamo la ciudad incendiada en Cuba colonial. Condiciones de vida durante la diáspora poblacional entre 1869-1879}

En la realidad bayamesa del año 1869, las condiciones políticas ocuparon un lugar central en la vida de la ciudad, se desencadenaba la primera guerra de liberación nacional y las consecuencias propias de todo enfrentamiento de similar naturaleza. Aunque la guerra no sólo afectó a Bayamo como región, el hecho denota una especificidad en la vida de sus habitantes, al sumarse otras consecuencias con el incendio de la ciudad y el recrudecimiento de la política colonial sobre todos aquellos que decidieron abandonar sus casas y refugiarse en el campo.

En numerosos diarios y cartas familiares se recogen las adversidades que pasaron las familias en los campos. Como generalidad comentan la presencia constante de bohíos en ruinas, que habían sido las moradas de las familias al principio de la guerra y luego convertidos en refugio para escapar del terrible azote de la guerra ${ }^{39}$. Para perpetuar el poder colonial se ajustaron leyes que justificaron nuevas formas de represión.

Es conocida campaña de reconcentración liderada por el Conde de Valmaseda y el jefe de operaciones Valeriano Weyler ${ }^{40}$, famosa por los crímenes y torturas que se llevaron a cabo para tratar de obtener noticias de los infidentes, mediante el sacrificio de sus familiares. El 14 de abril del año 1869 se promulgó la circular que daría cumplimiento a tales propósitos, se trataba de un conjunto de medidas que lejos de reglamentar el orden, influyeron para justificar los asesinatos y crímenes posteriores, entre ellas se encuentra la siguiente:

Serían pasados por las armas, todo hombre desde la edad de 15 años en adelante que esté fuera de su finca, así como incendiado todo caserío inhabitado o carente de un lienzo blanco en proclama de paz. Serían reconcentradas las mujeres que estuviesen fuera de sus respectivas fincas ${ }^{41}$.

El cumplimiento de estas disposiciones fue estricto. Sin embargo, las afectaciones mayores recayeron sobre los miembros más vulnerables de la familia: las mujeres y los niños. En testimonios recogidos por José Maceo Verdecia ${ }^{42}$, se esboza:

Asesinan a mujeres y niños, ancianos, saquean, ponen fuego, violan a la esposa en presencia del esposo, degüellan al hijo delante de la madre, y las mujeres reconcentradas son destinadas para pasatiempo sin respetar el dolor de la madre, la esposa, o la hermana ${ }^{43}$.

\footnotetext{
39 OKelly James, 1968, Ob.Cit., p. 126.

40 Valeriano, Weyler: Designado Jefe del Estado Mayor al mando del Conde Valmaseda, tenía la misión de recuperar la ciudad de Bayamo del poder de los independentistas.

${ }^{41}$ Maceo Verdecia, José, Bayamo, Editorial El Arte, Manzanillo, 1936, p.26.

42 José Maceo Verdecia nació en Bayamo, el 15 de abril de 1891. Fue escritor, autor del libro "Bayamo" donde relata la destrucción de la ciudad y el poco interés que muestran los sucesivos gobiernos republicanos por reconstruirla. Proviene de una familia de estirpe revolucionaria, fue su abuelo paterno, Pedro Maceo Infante, licenciado en farmacia, quien fuera el primero que prendió fuego a su propia casa el 12 de enero de 1869. A partir de aquí otros patriotas continuaron la misión de incendiar la ciudad completa.

43 Maceo Verdecia, José, 1936, Ob.Cit., p.26.
} 


\section{Diurkis Yarenis Madrigal León}

En lo que respecta a los asesinatos, revestidos de barbarie y monstruosidad, no está todo dicho. En las memorias inéditas del coronel Benjamín Ramírez Rondón, se recogen sucesos que describen eventos sádicos:

Los cadáveres de las jóvenes los habían puesto boca arriba, con los vestidos remangados hasta el estómago prueba inequívoca de que habían usado con ellas las mas refinadas maldades. Los cadáveres de las mujeres se hallaban en completo desorden, las cabezas de algunas jóvenes estaban separadas del resto del cuerpo ${ }^{4}$.

Después del incendio, la guerra prácticamente se concentró contra las mujeres y los niños. Al respecto comenta Francisco Estrada ${ }^{45}$ en una de sus cartas familiares:

Allí se ven ancianos respetables y encorvados, débiles niños e infelices mujeres en un estado casi completo de desnudez con los pies ensangrentados. No sabes las infamias que cometen estos bárbaros, aquí violan a todas las mujeres que cogen, hay niñas de ocho a diez años que las dejan a muerte. Es necesario mandarlas en camillas porque no pueden caminar ${ }^{46}$.

A lo largo de los diez años de lucha, son recurrentes los casos de asesinatos, fundamentalmente por parte de la camarilla del cuerpo de voluntarios ${ }^{47}$ a cargo del famoso asesino Lolo Benítez, quien transitó por los montes orientales, para dejar huellas sanguinarias en los familiares de los mambises y el resto de personas inocentes. De acuerdo con las narraciones de campaña, se ilustran señales visibles que permanecen como fenómenos sádicos en el historial de la guerra en este período.

[...] vimos desde la orilla del abierto una mujer al parecer estaba sentada [...] ni contestaba ni se movía, mandé á reconocerla y me dieron aviso que la mujer estaba muerta [...] La mujer había sido ahorcada y clavada en un tronco de mije que levantaba del suelo cerca de una vara, y que habían introducido por las partes genitales de la muerta, cuyo tronco le llegaba por el interior del vientre á mi parecer hasta el pecho [...] todos quedamos horrorizados de este espectáculo, cuya acción no se le ocurre ni á los bandidos más infames del mundo[...] $]^{48}$.

No fueron limitadas las ocasiones para hacer patente las crueldades por parte de la famosa camarilla de voluntarios al servicio del gobierno español. El nombrado

44 Ramírez Rondón Benjamín, Memorias de la guerra de 1868, (CNC) Casa de la Nacionalidad Cubana, Documento Inédito p. 26.

45 Francisco Estrada: Participó de forma activa en la guerra de los diez años, donde realizó importantes contribuciones militares. Su familia (esposa e hijos) se exiliaron con la finalidad de sobrevivir.

46 Estrada Francisco, Cartas Familiares, (CNC) Casa de la Nacionalidad Cubana, Documento Inédito, fecha 6 de mayo 1876, p 89.

47 Cuerpo de voluntarios: Tropa de hombres de nacionalidad cubana y española dirigidos por el gobierno español, para combatir al Ejército Mambí y la población civil relacionada con los infidentes.

48 Ramírez Rondón Benjamín, Ob.Cit., p. 89. 


\section{Bayamo la ciudad incendiada en Cuba colonial. Condiciones de vida durante la diáspora poblacional entre 1869-1879}

Lolo Benítez, utilizó todas las formas posibles para amedrentar los grupos de familias que permanecían en los campos. Una de las historias sádicas en extremo las realizó a una señora en gestación avanzada, quien suplicaba su libertad por causa de su embarazo, y por ser madre de familia al cuidado del resto de sus niños pequeños; la respuesta cruel y brutal avanzó sin escrúpulos hacia el grupo de familias prisioneras:

[...] y dicho Lolo se puso a mofar de la suplicante, hasta que al fin tirando éste de un cuchillo le dijo; vas á parir por la obra del Espíritu Santo, y le tiró una cuchillada estando la pariente parada, que le abrió el vientre desde el estómago hasta la vejiga, de donde descendieron los intestinos y la criatura ${ }^{18}$.

Los actos crueles acaecidos en las serranías del oriente del país muestran las barbaridades que muchas veces acontecen y se justifican en medio de la guerra; se trata de personas comunes, campesinos, gente de pueblo, que no tuvieron participación directa en la quema, ni en el movimiento insurrecto, simplemente resultaron víctimas por estar en el lugar y el momento equivocado.

\section{Las familias. Nuevos modos de vida durante la dispersión en los campos del Oriente de Cuba}

Las personas que logran sobrevivir en medio de las condiciones infrahumanas y la vida áspera propias de los montes, fueron participes de la asimilación de determinados patrones de vida, asumidos por la necesidad de subsistencia.

\section{La alimentación}

Las adversidades afrontadas en las serranías acaparaban el accionar de todos los actos cotidianos, por muy insignificantes que pudieran parecer. Los hábitos alimenticios sufrieron variaciones, ante la escasez se vieron obligados a tomar los aseguramientos naturales del monte. Las aves resultaron el tipo de carne más consumido, quizás por ser frecuentes en el hábitat de las serranías orientales. Según el diario de campaña del Coronel Benjamín, concurrían los tejones, palomas torcazas y guaneras, la perdiz, el perico y la camá, además de jutías pequeñas que vivían en palos y huecos ${ }^{49}$. Sobre otras formas de lograr provisiones en medio de situaciones adversas comenta:

Los recursos de alimentación estaban muy escasos y muchos días los pasábamos comiendo cañas y carne de jutía sin sal [...] ${ }^{3}$.

[...] pués solo habíamos comido en dos días algún poco de miel de castilla con palmito $[\ldots]^{4}$.

${ }^{49}$ Ramírez, Rondón Benjamín, Ob.Cit., p. 252. 


\section{Diurkis Yarenis Madrigal León}

Al siguiente día, salí en marcha para Jiguaní [...] nos desayunamos con unos panales de miel de abeja y un sancocho de yerba mora, hojas de calabazas y retoño de bejuco de boniatos [... ${ }^{5}$.

Las familias que vivían por aquellos lugares se mantenían con jaibas con una especie de camarones que llaman viejas, viandas y miel de abejas y como grasas manteca de coco [...] 6 .

El consumo de sal para sazonar las carnes, constituyó una de las tantas necesidades indispensables, para resolverla no faltaron las innovaciones. Sobre este aspecto relata:

[...] se hacían calderos con agua del mar que se hervía, dejándola luego hasta que cuajaba. Operación que se practicaba de noche por temor de que el humo de las hogueras fuese visto por los tripulantes de las lanchas cañoneras que vigilaban la costa $[\ldots]^{50}$.

Obtener la sal a partir de las plantas del campo, resultó otra de las variantes concretadas con frecuencia. En la obra Recuerdo de la Guerra de los Diez Años, José María Izaguirre ${ }^{51}$ relata una de las alternativas muy utilizada en ese período de guerra: "Se cogen dos troncos de macaca como de cinco cuartas de largo, sobre ellos se asientan rajas de leñas y se le da fuego hasta reducirlos a cenizas, se le echa agua, se hierve y se convierte en sal de espuma"52.

Una de las novedades apreciable en la guerra, resultó la forma utilizada para innovar un tipo de bebida a la cual llamaron "cerveza de fruta de jagua". Sobre este particular comenta:

[...]Este consistía en un poco de cerveza de fruta de jagua y embazada en unos canutos de caña de bambú. La cerveza era muy buena, pues al quitar el tapón de cedro fermentaba y tenía el amargo natural de la cáscara de la fruta de jagua y además un olor agradable, y creo que si se estableciese una fábrica de cerveza de esa fruta con buenos aparatos habia de competir con todas las cervezas del mundo ${ }^{11 .}$

Igualmente, tuvieron la necesidad de establecer sembrados denominados "cultivo de subsistencias", fundamentalmente basados en la siembra de viandas como boniatos, yucas y malangas. Estos alimentos tienen como característica su reproducción bajo la tierra, ello permitía la recuperación parcial de los alimentos, en caso de que el enemigo llevara a cabo la tea incendiaria en sus sembrados.

\section{El vestuario}

\footnotetext{
50 Ramírez, Rondón Benjamín, Ob.Cit., p. 253.

${ }^{51}$ José María Izaguirre: patriota y pedagogo, nacido en Bayamo 14 de mayo de 1828. Fue general del Ejército Libertador de Cuba durante la Guerra de los Diez Años. Tuvo la misión de viajar a Jamaica y luego a Estados Unidos para recaudar fondos para la lucha y contactar a los exiliados cubanos a favor de la unidad. Publicó un libro llamado "Asuntos Cubanos", el cual narra sucesos de la Guerra Grande (1868-1878).

52 Izaguirre, José María, (S.F.), Ob.Cit., p. 99.
} 


\section{Bayamo la ciudad incendiada en Cuba colonial. Condiciones de vida durante la diáspora poblacional entre 1869-1879}

En la misma medida el vestuario sufrió cambios. Los años de sacrificio por los campos orientales, sin morada fija, ni condiciones para mantener una higiene correcta agudizaban el logro de alternativas cotidianas.

Por otra parte, se encontraba la realidad característica de esos espacios geográficos, situados en las cercanías de la Sierra Maestra, cadena montañosa insertada en la región suroriental del país. Obviamente en tales circunstancias se acrecentaron las dificultades, por la recurrencia de caminos inaccesibles, marcados por continuos desfiladeros, precipicios y manigüeros de espinas punzantes que imposibilitaban el tránsito a pie y fundamentalmente a caballo.

De igual modo, prevalecían otras incidencias como la lejanía de las zonas pobladas, donde resultaría oportuna la presencia de establecimientos destinados para el comercio; estas realidades corroboran la presencia de un sinnúmero de irregularidades para el andar diario que imposibilitaba la adquisición de nuevas prendas para vestir. Las circunstancias trajeron como consecuencia el deterioro de ropas y zapatos, y por ende, la necesidad de enfrentar la realidad de acuerdo con las condiciones inmediatas. No resultaría extraño que las mujeres anduviesen semidescubiertas, con los vestidos ajados y rotos. Sobre este particular narra el diario de guerra:

[...] las noches eran obscuras [...] las mujeres podían hacer velas con pábilo de jaguey cuyas mechas daban buen resultado [...] muchas veces los vi vestidos con cáscaras de jagüey o guacacoa de cuyas cáscaras machacadas hacían camisas, pantalones, hamacas y frazadas [...] Esta clase de ropa se acostumbraba mucho obligado por la necesidad, sobre todo, en la clase civil y en los enfermos y rezagados militares también se hacían especies de alpargatas de majagua para calzado. Muchas mujeres y niños se vestían también con esa clase de vestidos, a fin de no andar desnudos. La pluma más elocuente no es capaz de describir las miserias y vicisitudes experimentadas por los patriotas cubanos ${ }^{53}$.

Los grupos insurrectos también presentaban necesidades impresionantes, no solo por las condiciones en el vestuario y calzado, a ello se suman las debilidades por causa del hambre y las enfermedades. Sin embargo, tales vicisitudes no resultaron obstáculo para continuar la guerra.

Las fuerzas insurrectas en general estaban casi desnudas y descalzas. La mayor parte de nuestros soldados cubrían sus carnes con un pantalón que no le llegaba más que a la rodilla, por haber utilizado la parte de abajo para remendar el resto. Otros iban cubiertos con un pedazo de lienzo viejo amarrado por la cintura, llevando la parte superior del cuerpo desnuda. Los jefes y oficiales iban muchos cubiertos con harapos; todos estábamos infestados de caránganos y piojos, cuyos insectos se pasaban de unos á otros por la falta de aseo [...] ${ }^{13}$.

\section{Enfrentamiento a las enfermedades}

53 Ramírez Rondón Benjamín, Ob.Cit., p. 208. 


\section{Diurkis Yarenis Madrigal León}

La carencia, unida a la necesidad de sobrevivir, posibilitó el desarrollo de ciertas prácticas de sabiduría popular, como el empleo de métodos e innovaciones a partir de las plantas para curar enfermedades. Por supuesto, comenzaba a jugar su función la herencia de la cultura popular arraigada por los ancestros y trasmitida hacia los nuevos descendientes.

Fue de gran utilidad la miel de abejas como antibacteriano, la majagua como coagulante ante grandes heridas, la resina de copal con miel para los estados gripales, así como los cocimientos de caña santa, importantes para equilibrar la presión arterial. Para los problemas estomacales era muy utilizada la agrimonia, para la anemia la cañadonga con miel y el jengibre como estimulante. El parasitismo se trataba con apasote y raíz de paraná; por otra parte, los resfriados fueron potencialmente combatidos con hojas de salvia ${ }^{54}$.

En medio de tantas problemáticas para afrontar la vida sobresalen acontecimientos traumáticos que muestran el curso de las enfermedades en un estado desgarrador. Debido a la carencia de recursos y unido a la necesidad de sobrevivir se utilizaron alternativas disímiles, aunque muchas veces resultaron inexactas y desatinadas al punto de no considerarse adecuadas para suplir las complicaciones de las heridas y traumas internos que presentaban los lesionados. Ello condujo a incontables bajas del Ejército Mambí por causa del fallecimiento o por formar parte de los grupos de paralíticos, mutilados e impedidos físicos visiblemente imposibilitados para continuar la guerra. Aspectos tan deprimentes en esta esfera son comunes en las narraciones del Coronel Benjamín: lisiados

También dimos baja á varios enfermos de úlceras que estaban ya imposibles, todos para caminar [...] la enfermedad de llagas entre nosotros se hacía temible, pues, unos morían por falta de recursos, y otros de los que se sanaban quedaban lisiados 14.

[...] y como la fetidez que despedían los heridos no, nos dejaba estar tranquilos, los puse á que se lavasen bien las heridas, haciéndole lavar también la parte de ropa que los cubría y que estaba impregnada de humor.

[...] me quedé horrorizado al verle la gusanera que tenían en las heridas [...] nos pusimos, [...] con unas paleticas á flor de agua á sacarles los gusanos. En esa operación tuvimos largo rato; pero eran tantos los bichos que no era posible quitárselos todos y entonces determiné que nos pusiéramos á rayar la corteza de las naranjas verdes y [...] ponerle la resina que no se cayese y entonces se me ocurrió sacar unas cáscaras de guamá y hacerlas pedazos al tamaño de las heridas y amarrarlas con majagua [...] $]^{15}$.

54 Datos extraídos de la conferencia "El campesinado y su vinculación con la lucha revolucionaria en la región del Valle del Cauto" dictada por Víctor Marrero en la Casa de la Nacionalidad Cubana, durante la 8va edición de la Fiesta de la Cubanía. 


\section{Bayamo la ciudad incendiada en Cuba colonial. Condiciones de vida durante la diáspora poblacional entre 1869-1879}

Más tarde, el Coronel Benjamín Ramírez Rondón ${ }^{55}$ sufrió en carne propia la epidemia de los insectos llamados aradores. La picazón y el desasosiego le hicieron idear por sí mismo una forma de curarse; sobre la cual relata:

[...] Luego tomé tres purgantes; pero á todo esto los aradores y la picazón se me aumentaban más y más y un día desesperado hice, que Joaquín Toro le sacara á diez cápsulas de mi remito la pólvora y la echara en una jiguera exprimiéndole unos cuantos limones y después de bien batidas estas sustancias puse que [...] me untara por las espaldas nalgas y piernas, mientras tanto yo me embarraba el cuello, la cara y demás partes delanteras. Concluida esta operación [...] empezó á secarse la untura [...] y aumentaba el ardor y el fuego parecerme estar metido en un volcán. [...] salí casi sin juicio [...] y fui á dar á la costa del rio [...] desnudo en pelota [...] cesó el ardor [...] ${ }^{16 .}$

Con el transcurso de los años, el tránsito por montes y serranías, posibilitaron el establecimiento de una conciencia de vida cotidiana en campaña, que aunque fuese una alternativa funcional, marcaría la psiquis humana con un efecto severo de desgarramiento, fundamentalmente desde el punto de vista emocional, debido a la presencia perenne de la tortura y de la muerte en sus diversas variedades.

En esas condiciones proliferó con arraigo la asimilación de recursos religiosos, como forma de consuelo, refugio y justificación sobre realidades inexplicables que constantemente afloraban en todos los espacios. En circunstancias como estas se expresan disímiles emociones: amor, odio, compasión, desprecio, nostalgia, repugnancia y lógicamente los deseos desproporcionados de venganza unido a raíces de amargura y resentimiento. Todos emergen como respuestas a la perenne incertidumbre vivenciada en la guerra, ante el hecho de comprender la fragilidad de la vida y corroborar que la muerte podía ser tan real.

\section{Normas de comportamiento cultural}

Las adversidades no significaron un obstáculo para el continuo fomento de ciertas particularidades culturales. Los patrones propios de la cultura, aprendidos y asumidos desde la cuna familiar, se manifestaron continuamente como mecanismos establecidos desde el punto de vista conductual. Evidencia de ello lo expone Máximo Gómez Báez en su Diario de Campaña:

[...] reunimos las familias de Gómezy Cisneros; se le dio una comida y se pasó la noche un tanto divertida; todo con mucho orden y moralidad. Algunas horas pasé contemplando nuestra agreste reunión, debajo de las palmeras, pues había mucho de poesía pero de aquella poesía sublime que se siente en el alma y que habla al corazón. Nadie mas que nosotros mismos que sobrellevamos la vida azarosa de una guerra, como la que hace cinco años venimos sosteniendo, puede formarse una idea de cómo

\footnotetext{
${ }^{55}$ Benjamín Ramírez Rondón: nacido en Bayamo, en el seno de una familia acomodada. Adquirió el grado de Coronel durante su participación activa en la guerra de los diez años. Escribió importantes notas y apuntes sobre la guerra, que más tarde formaron parte del documento inédito "Memorias de la guerra de 1868" donde se detallan numerosos acontecimientos experimentados durante la etapa bélica.
} 


\section{Diurkis Yarenis Madrigal León}

se regeneran las costumbres de un pueblo por medio de una guerra que lo haga independiente.

Como se nota que cada individuo se respeta así mismo y el orden y la moralidad que reina en el seno de la familia consolida el bienestar de la sociedad, y en la reunión de que hago mención todo esto se podía estudiar. Sí porque debajo de unas palmeras en medio de un bosque, un grupo de hombres y mujeres se conducían como si fuese un salón de refinada etiqueta ${ }^{56}$.

Otros parámetros de la vida cotidiana también mostraron su curso. Se fomentaron uniones maritales y los consecuentes partos en la manigua, aunque en reiteradas ocasiones madres e hijos estuviesen en peligro de muerte, a causa de las difíciles condiciones de vida ${ }^{57}$. Sin embargo, significativo resulta el empeño de las familias para proseguir con las reglas culturales, tal es el caso de la costumbre de bautizar a los recién nacidos, con la correspondiente designación de padrinos y madrinas y el agua de socorro.

Tales costumbres se mantenían con un significado especial. Las familias que decidieron resistir los rigores de la guerra se enfrentaron a ciertos cambios culturales, pero al mismo tiempo trataron de revivir aquellos indicadores conductuales que formaron parte de sus normas, hábitos, e idiosincrasia socializada e internalizada desde el plano familiar.

De esta manera, puede considerarse la coexistencia de dos modelos en el comportamiento cultural: por un lado el mantenimiento de algunos patrones y por el otro, la incorporación de nuevos hábitos para conservar la vida. El primer modelo estuvo determinado por el sostén de ciertas pautas de conductas, como forma evidente de comprender que las normas y las reglas del comportamiento no cambian de forma drástica, a pesar de la exposición del ser humano ante cambios traumáticos en el cotidiano de vida. En un segundo caso, se destaca la incorporación de formas de vida influenciadas por la necesidad de subsistencia. Fue preciso asumir nuevos mecanismos para suplir las necesidades de alimentación, vestuario y curar las enfermedades, que dado el tiempo transcurrido fueron adoptados como hábitos oportunos dentro del sistema cotidiano.

Indudablemente, mantener el orden y la moralidad entre los grupos familiares, constituía un patrón demasiado arraigado en el acervo cultural de los moradores del siglo XIX. En virtud de ello, tales concepciones no podían cambiar de forma brusca frente a las nuevas realidades.

La inestabilidad de la vida en las serranías, las plagas (roedores, mosquitos y jejenes), los brotes de enfermedades (cólera, tifus), el déficit alimenticio, la persecución constante de las tropas españolas y de voluntarios, entre otras cuestiones; condujeron a la decisión de numerosas familias de salir de los montes. Tenían dos posibles variantes; el exilio o acogerse a las exigencias del gobierno español en la ciudad arrasada.

56 Gómez Báez, Máximo, Diario de Campaña, La Habana, Instituto del Libro, 1968, p.8.

57 Milanés, Jorge Carlos, Diario de Guerra, (CNC) Casa de la Nacionalidad Cubana, Documento Inédito, p.12. 


\section{Bayamo la ciudad incendiada en Cuba colonial. Condiciones de vida durante la diáspora poblacional entre 1869-1879}

\section{La ciudad arruinada}

La desarticulación de la ciudad después del incendio fue evidente. De acuerdo con los datos censales, en la primera etapa de la contienda bélica (1868-1878), la reducción poblacional fue intensa. En 1870, existía un total de 24592 habitantes; esta cifra, comparada con 33673 que era el número de moradores en el año 1862, denota una reducción de más de 9000 vecinos. En los años sucesivos continuó el descenso hasta 1877, a partir de esta fecha, se evidencia un incremento poblacional, el cual se mantuvo con cierta estabilidad hasta el fin de la época colonial ${ }^{58}$.

Este déficit poblacional influyó en los movimientos socio demográfico de la región, fundamentalmente en lo que respecta a la nupcialidad. Teniendo en cuenta la revisión de las actas matrimoniales, se comprueba que entre los años 1870 a 1877, se reporta un bajo número de matrimonios. En siete años sólo se registran veinticinco casos, aumentando a treinta y tres a finales de la década.

De igual forma sucedieron los nacimientos. Según las actas resultaron frecuentes las inscripciones de niños, reconocidos por vía materna y declarada como hijos naturales. Como generalidad formaban parte de familias de madres solteras que asumieron el cuidado y protección de sus hijos, sin la presencia paterna ${ }^{59}$.

Evidentemente este comportamiento tuvo su base en la realidad del ambiente sociopolítico, el cual acaparó la atención de los moradores, sin permitir entre los habitantes de la comarca la normalidad cotidiana. Pasarían muchos años para la presencia de oportunidades significativas en función del habitual desenlace de los procesos cotidianos en la región.

58 Mari Aguilera, Idelmis, Bayamo en el último tercio del siglo XIX, Editorial Bayamo, Bayamo, 1999, pp.44-45.

59 El hecho de prevalecer este tipo de inscripciones, sugiere la probabilidad de un alto número de madres solteras, tal vez, mujeres que vivían en relaciones consensuales o vinculadas con hombres casados que mantenían relaciones extramatrimoniales. 
La pésima situación económica imposibilitó la reconstrucción de la ciudad y con ella de las viviendas para estabilizar la vida dentro del hogar. En los acuerdos del ayuntamiento aparecen constantes reclamaciones para rehacer las casas en estado ruinoso, incluso con los mismos materiales recuperados del derrumbe que causó el incendio.

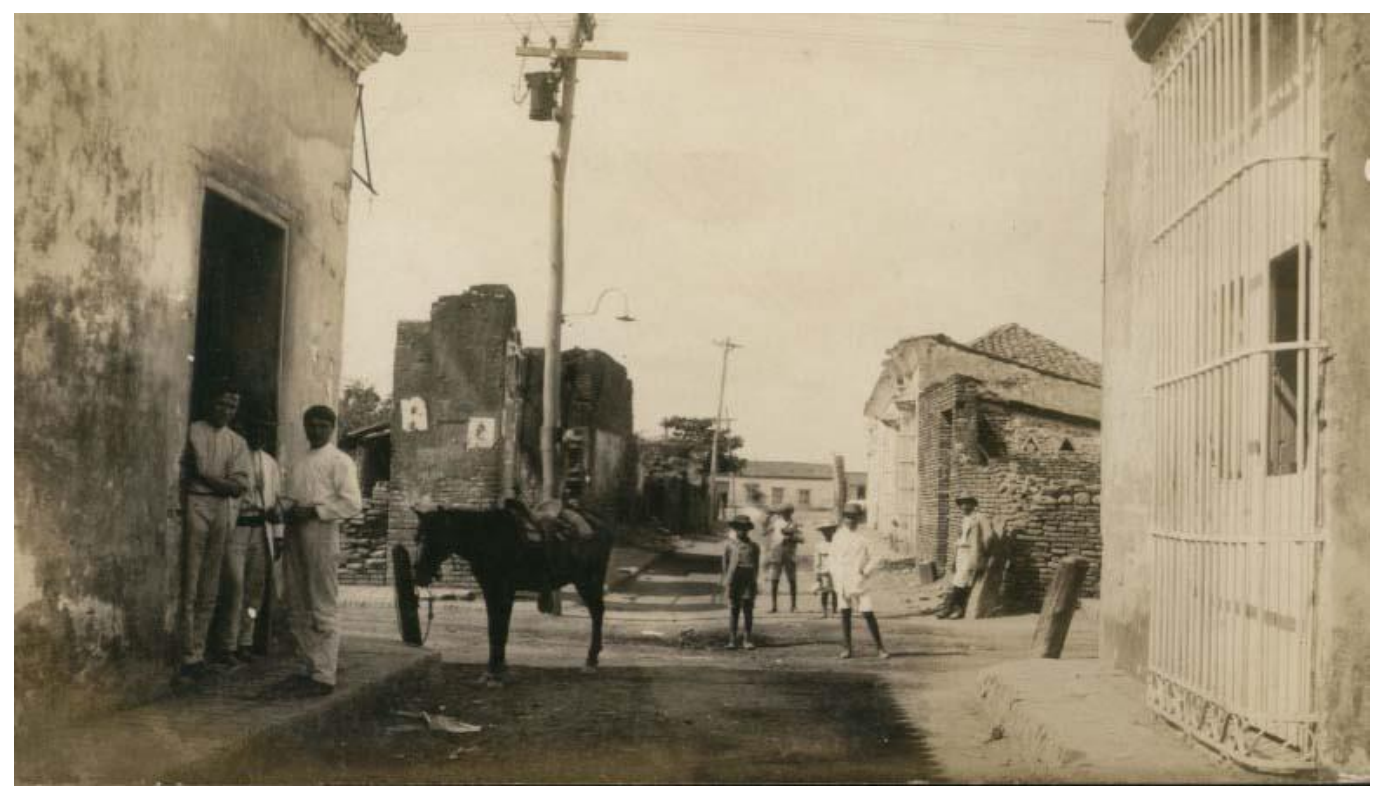

Igualmente aparecen solicitudes de personas que reclaman sus derechos por la residencia que ocupan, exigen el certificado de bienes no embargados por el tiempo que llevan en su uso personal y no en manos de los infidentes. Estamos en presencia de necesidades insatisfechas, tener un hogar constituye un elemento de primer orden para llevar a cabo la supervivencia familiar, probablemente determinado número de familias permanecieron hacinadas con parientes y amistades o quizá durmiendo junto a los escombros y a la intemperie, hasta lograr con el paso del tiempo un espacio donde pernoctar.

Mientras tanto en la arruinada ciudad, el Gobierno Superior Civil instauró medidas para repoblar la zona. En marzo de 1870 y nuevamente en el año 1871 se dispusieron órdenes para distribuir solares y terrenos embargados a todas aquellas personas dispuestas a trabajar a pesar de las ruinas y el fuerte debilitamiento del sistema económico y comercial. Sin embargo, tales alternativas no fueron suficientes para atraer la totalidad de los grupos de familias que en masa vagaban por los montes, ni aquellos que permanecían en el exilio.

Existían razones marcadas que detenían el regreso espontáneo de los hijos de Bayamo: El aborrecimiento hacia el régimen colonial, el severo desgarramiento emocional por tanta destrucción y muerte de seres queridos y la cruel devastación económico social que paralizó la actividad económico-comercial, la vida social, instructiva, educativa y cultural en el más amplio sentido del significado. Los protocolos del Ayuntamiento exponen actas que evidencian ese proceso; por ejemplo, con fecha del 31 de octubre de 1872 se expresa: 


\title{
Bayamo la ciudad incendiada en Cuba colonial. Condiciones de vida durante la diáspora poblacional entre 1869-1879
}

\begin{abstract}
D. Juana Samarra Roget agradece al Gobierno de Bayamo por haberle facilitado en un barco pasaje a ella y su familia para trasladarse del Cauto hasta Manzanillo donde permanecerá hasta que pueda volver a la ciudad ya que carece de todo recurso ${ }^{60}$.
\end{abstract}

Una gran parte de las familias que emigraron hacia Jamaica -principalmente las familias de los patriotas de la guerra- se trasladaron hacia otros destinos como New York y Europa; por otra parte, aquellas familias -en menor medida comprometidas con la guerra- se mantuvieron en Kingston como estancia temporal hasta concluir la etapa de emergencia bélica, para luego regresar a Bayamo.

Los protocolos del Ayuntamiento recogen documentos sobre las transacciones legales que realizaron algunas familias ${ }^{61}$ que permanecían en Jamaica. Tales grupos otorgaban poderes a residentes de la ciudad para que realizaran todo tipo de negociación económica o judicial (ventas de propiedades, administración de sus bienes, entre otros fines).

En otras circunstancias se encontraban aquellos que iniciaron un retorno paulatino para acogerse al sistema de leyes y ordenanzas del gobierno español, principalmente se trataba de personas pobres, sin recursos, labradores, negros y mulatos acosados por la barbarie y el desasosiego que por años experimentaron en la manigua.

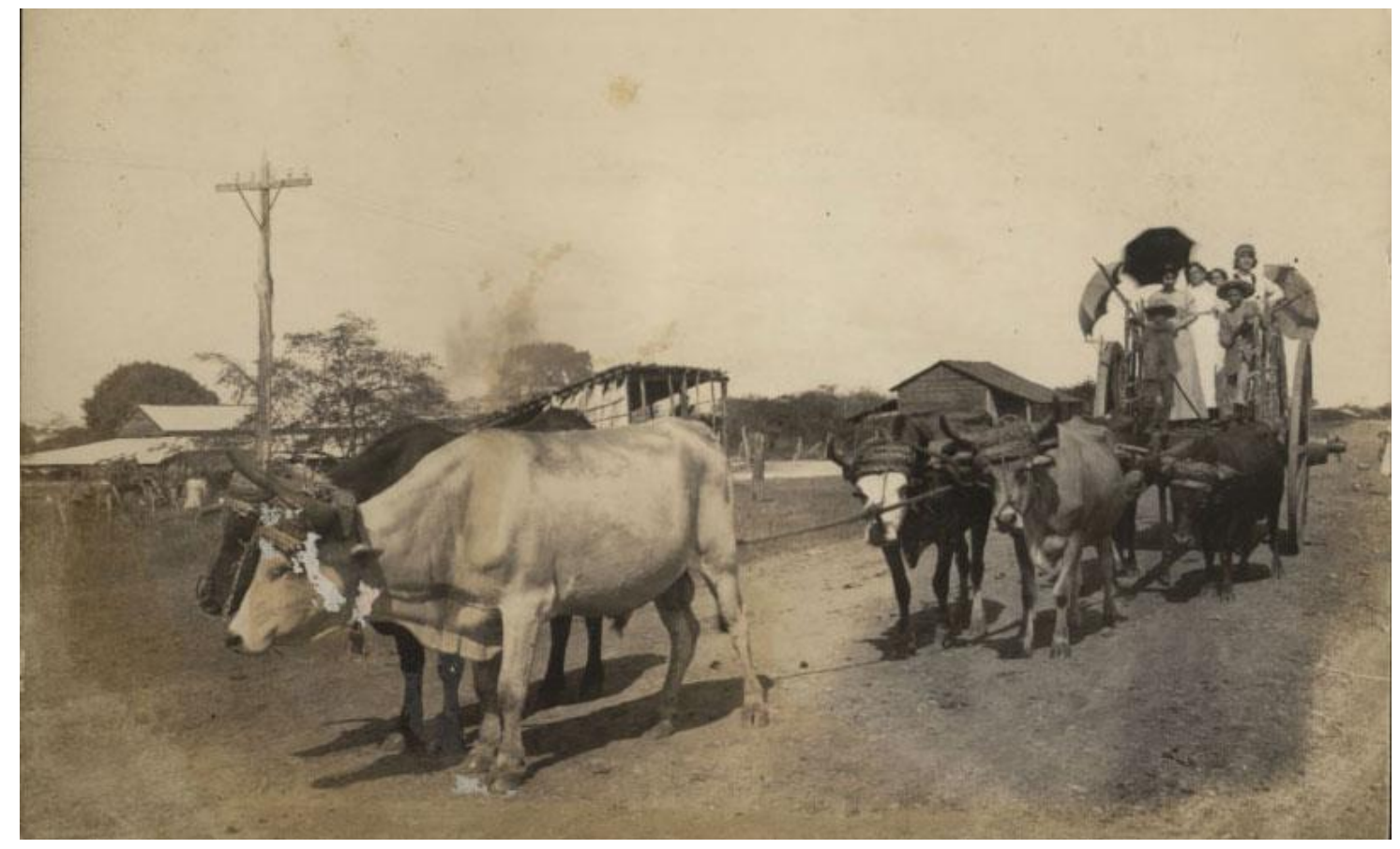

60 (CNC) Casa de la Nacionalidad Cubana, Sala de Información, Fondo Colonia, Protocolos del Ayuntamiento 1872.

61 Entre las personas que vivían en Jamaica no solo se destacan las familias de los patriotas que iniciaron la guerra, también se encontraban familias adineradas y otras con menores recursos que se decidieron por el exilio como forma de protección hasta concluir la guerra. No existen datos cuantitativos sobre el número de familias que se exilió en Jamaica ni en otros países; las evidencias estudiadas afloraron desde fuentes orales. 
La vida citadina se transformó en un ambiente ruralizado, no sólo debido a la reconstrucción de viviendas desde modelos campesinos, también se insertaron estilos de vida caracterizados por prácticas agrarias para satisfacer las necesidades humanas de primer orden. En ese caso resultó apropiada la construcción de pequeñas parcelas de cultivo, ideales para sembrar algunos productos (viandas) destinados a la supervivencia cotidiana.

De forma constante las actas del Ayuntamiento expresaban la triste situación del vecindario reducido a escombros y la solidaridad de algunas familias que alojaban en sus casas a los habitantes que retornaron de los campos, cansados y asolados por epidemias, descalzos, hambrientos y carentes de vestuarios ${ }^{62}$.

En la ciudad se hizo desesperante la carencia de alimentos, esta constituyó la más urgente de las necesidades, aunque no fue la única. Hacia el año 1871 reiteraban las solicitudes del gobierno local al Departamento Oriental reclamando providencias para el socorro de las familias enfermas. Se multiplicaban los inválidos e incluso los enfermos con lepra, sarna, úlcera, entre formas malestares causados por fiebres agudas. Las camas del hospital civil eran insuficientes para socorrer el número de heridos y enfermos que constantemente arribaban a la ciudad.

Hacia el año 1874 el gobierno municipal ya contaba con planillas para relacionar el número de personas interceptadas en los caminos y pueblos cercanos, generalmente se trataba de familias que aludían la necesidad de buscar alimentos en terrenos rurales.

Una de las alternativas que el gobierno propuso fue la construcción de un asilo provisional para recluir a los diversos grupos de familias pobres y sin hogar que vagaban por las calles ${ }^{63}$. Surgió así la idea de levantar barracones compuestos por embarrado y guano que tendrían el doble propósito de hospital y refugio, de esa manera, los necesitados podrían ejercer algunos trabajos con el yarey al tiempo que estarían vigilados por los delegados de la autoridad ${ }^{64}$.

También es contundente el elevado número de mujeres que asumieron la posición de cabezas de familias con la responsabilidad de mantener hijos, enfermos, ancianos, inválidos, huérfanos entre otras personas y parientes necesitados. Los pocos casos donde se hace referencia al amparo de hombres adultos, eran justificados por la presencia de enfermedades o la incapacidad de movilidad física, debido a su estado senil. Esta relación nominal fue más constante en el Dátil, Laguna Blanca, El Horno, el Partido del Naranjo y Guisa ${ }^{65}$.

La realidad social y cultural donde estuvo inmersa la población, reveló el fuerte peso del estado de deterioro. En la cotidianidad social se manifestaban

62 (AHP) Archivo Histórico Provincial, Fondo Colonia, Acuerdos del Ayuntamiento 5 de marzo 1870.

63 No es posible contabilizar el número de personas que fueron acogidas por las medidas gubernamentales, en tanto no existen datos exactos contabilizados en la época.

64 (AHP) Archivo Histórico Provincial, Fondo Colonia, Leg. 1-14, Acuerdos del Ayuntamiento 1871.

65 (AHP) Archivo Histórico Provincial, Fondo Colonia, Leg. 2, Expte.32, 33, 34, 35, 36,37, Acuerdos del Ayuntamiento 1874. 


\section{Bayamo la ciudad incendiada en Cuba colonial. Condiciones de vida durante la diáspora poblacional entre 1869-1879}

irregularidades en el orden público, por la permanencia de menesterosos, vagos, borrachos y rateros ${ }^{66}$. Esta problemática persistió hasta el fin de la época colonial, existen reiteradas notificaciones de patrullajes nocturnos en los campos, por los constantes robos, pleitos, bandolerismo, querellas públicas, crímenes y secuestros lo cual trajo consigo varias solicitudes para reforzar el funcionamiento fiscal en protección de las familias desamparadas.

En medio de ese clímax se aceleraron actos de fraude como indicadores de una corrupción generalizada, a tal punto que bajo el amparo de la ley de embargo se justificaban las faltas e infracciones contra líderes del levantamiento en armas. La ley permitía utilizar las casas de los infidentes para tomar provecho a través de su alquiler además de cualquiera de sus pertenencias, terrenos y esclavos.

Obviamente aumentaron las formas para hacer fortuna a partir de la malversación, el fraude y la estafa de algunos dueños de establecimientos que tomaron provecho de los sucesos. Una de las medidas más desvergonzadas fue el robo de los materiales que pertenecían a las viviendas de los insurrectos, utilizados para reconstruir casas y establecimientos privados.

El desorden generalizado también influyó sobre el movimiento interno de la gran masa de esclavos residentes en la localidad. El hecho de no contar con documentos legales trajo consigo disputas judiciales por parte de los dueños de esclavos que solicitaban su devolución, el resto se mantenían hacinados en el llamado "Depósito de Esclavos" para ser alquilados por cuentas del gobierno, hasta que los patrones, quienes estaban ausentes en ese momento, hicieran solicitud formal como parte de sus bienes económicos.

En medio de tales circunstancias, no faltaron las reclamaciones de negros y mulatos que manifestaban su condición de emancipados mucho antes de estallar la guerra, mientras que otra gran parte de esclavos pertenecientes a líderes del levantamiento e insurrectos continuaban como prófugos en diversas zonas de oriente y el centro del país ${ }^{67}$.

En el año 1878, la guerra llegó a su fin y con ello nuevas medidas en función del reordenamiento del sistema socioeconómico bajo las condiciones de paz. Entre los días 3 y 4 de julio del mismo año se rectificó la fuerza legal de la circular emitida el pasado 28 de noviembre de 1877 por el Gobierno Superior Civil, la que establecía la entrega de bienes a herederos de los infidentes ${ }^{68}$.

En días sucesivos se incrementó el desplazamiento poblacional amparado por el decreto de nuevas leyes. Las estipulaciones admitían el reparto de terrenos públicos y la eximición de toda contribución y gravamen a las fincas urbanas existentes o de nueva construcción, además de liberar de contribuciones por el

66 (AHP) Archivo Histórico Provincial, Fondo Colonia, Leg.152, Expte. 2627, Acuerdos del Ayuntamiento 1874.

67 (AHP) Archivo Histórico Provincial, Fondo Colonia, Leg. 4 y 5, Acuerdos del Ayuntamiento 1874.

68 (AHP) Archivo Histórico Provincial, Fondo Colonia, Actas del Ayuntamiento año 1878. 


\section{Diurkis Yarenis Madrigal León}

término de cinco años a las fincas de todo género que habían sido arruinadas por causa de la guerra e incluso exonerar del pago por tres años a todas las industrias y comercios de los Departamentos Oriental y Central ${ }^{69}$.

Dentro de los patrones culturales, las familias experimentaron determinados cambios. En sus memorias, el coronel Benjamín Ramírez hace alusión en su regreso a la ciudad con un doloroso sentir:

Tendí mi vista a mi alrededor y divisé llanuras, donde antes habían edificios, tropezaron mis ojos con las Sierras [...] lagrimas brotaron a mis ojos.

Las costumbres habían sufrido también una metamorfosis completa. La generosidad y la honradez (cualidades propias de los hijos de Bayamo) habían sido desplazadas por la avaricia y la malignidad. Aquellos sublimes cantos liberales que antes entonaban sus habitantes [...] habían sido sustituidos por cantos serviles y aduladores.

La música como expresión de la realidad, afirmaba el decaimiento de ánimos de los moradores, no se escuchaban las serenatas de los jóvenes enamorados, en su contrapartida se elevaban pequeños órganos nocturnos o grupos de asiduos a las tabernas donde entonaban canciones como la malagueña y la jota ${ }^{70}$.

A partir de esta fecha comenzó un movimiento poblacional mucho más intenso hacia Bayamo; se trataba de una etapa en la cual una gran parte de los moradores de la ciudad regresaban con el objetivo de ocupar sus domicilios y propiedades abandonadas después del incendio. El hacinamiento de familias resultó tan intenso que el Comandante General de Bayamo solicitó ayuda al Gobernador Político de Oriente, para atenuar el curso de las nuevas necesidades primarias que surgían como resultado de las aglomeraciones de la población; el acuerdo exigía la competencia de guardias municipales para velar por el orden y la limpieza pública ${ }^{71}$.

También retornaron algunos de los insurrectos en unión de sus familias quienes resistieron la contienda en las serranías. Una expresión detallada la expone en sus memorias el coronel Benjamín Ramírez Rondón el día de su regreso:

Llegada la hora de las sombras apareció la población ante mi vista, semejante a un osario cubierto de negro crespón, en donde se interrumpía a veces el silencio nocturno por la música de algún organillo que dado al estado de decaimiento de ánimo en que me hallaba sumido llegaba a mis oídos produciendo un sonido fatídico cual el de las de la noche.

Para colmo de mis desgracias me hallé también que mis condiscípulos y amigos de la juventud así como mis compañeros de armas habían desaparecido quedando solamente un quince por ciento de aquellos que habían salido para la guerra $^{72}$.

${ }^{69}$ (AHP) Archivo Histórico Provincial, Fondo Colonia, Actas del Ayuntamiento año 878.Leg. 63, Expte.1103; leg. 66, Expte. 1153

70 Ramírez Rondón Benjamín, Ob.Cit., p. 232.

71 (AHP) Archivo Histórico Provincial, Fondo Colonia, Acuerdos del Ayuntamiento 10 de abril de 1878, p.6.

72 Ramírez Rondón Benjamín, Ob.Cit., p. 281. 


\section{Bayamo la ciudad incendiada en Cuba colonial. Condiciones de vida durante la diáspora poblacional entre 1869-1879}

Si bien, diez años después del incendio de la ciudad resultaron siglos para los bayameses que albergaban esperanzas, ilusiones y sueños; estos jamás fueron congruentes con la realidad que divisaron cuando finalizó la guerra. Desde entonces el sentir de los hijos de Bayamo se hizo notable, la población en su conjunto sufrió los avatares de la destrucción, de alguna manera todas las familias vivenciaron y experimentaron vicisitudes, pérdidas y cambios en diversas magnitudes.

\section{Consideraciones Finales}

En Bayamo después de la quema de la ciudad, se produjeron cambios en el sistema de instituciones propios de la época, en el comercio, la economía, la salud y la vida educacional. La situación se tornó más difícil, en la medida que se recrudecieron las medidas del gobierno español contra los bayameses que regresaron de forma paulatina. De igual modo, al interior de la ciudad destruida por el incendio, se produjeron transformaciones en los estilos, conductas y comportamientos, la vida ciudadana se desdibujó en función de la subsistencia.

El incendio de la ciudad selló en Bayamo un nuevo período; más allá de consecuencias políticas, socio-económicas, culturales y de otra índole, marcó comportamientos, sentimientos, emociones y todo un conjunto de posicionamientos subjetivos que desde entonces se han expresado como comportamientos nostálgicos por el pasado glorioso de la ciudad.

Culminó la contienda bélica en 1898 y con ella las traumáticas situaciones que afloraron con el incendio, la devastación y la guerra. La ciudad de Bayamo no fue la misma, sus casas, calles, plazas estaban muy distantes del esplendor pasado. Entre emigraciones, exilios, desapariciones y muertes, la población tampoco resultó igual, las personas que legaron epopeyas en el escenario cultural ya no estaban, familias enteras habían desaparecido sin margen preciso para tejer las genealogías del árbol familiar. Bayamo se convirtió en un nuevo reflejo de cambios significativos. La nueva centuria trajo otros objetivos que acapararon la mirada de los bayameses, la lucha por la vida atesoró la atención de toda la comarca, el deseo por revertir su figura arruinada y estancada en sus propios límites se convirtió en un espejismo obsesionado.

El nuevo siglo fue partidario de una férrea pelea por su reconstrucción, las ansias por la restauración de la añorada ciudad se arraigaron en el espíritu de sus gentes; poemas, canciones, libros, versos, baladas, trovas, escritos periodísticos y todo tipo de expresiones comenzaron a ser notables hacia todas las latitudes. El grito apasionado por el renacer del Bayamo amado, se elevó como parte de una deuda contraída con el pasado heroico y que desde entonces simbolizó la resistente lucha por lograr el renacimiento de la ciudad. 


\section{Diurkis Yarenis Madrigal León}

Bibliografía

Aguilera Rojas, Eladio, Francisco Vicente Aguilera y la Revolución de Cuba de 1868, La Moderna Poesía, La Habana, 1909, p.60.

Céspedes Argote, Onoria, Cartas familiares de Francisco Vicente Aguilera, Ediciones Bayamo, Bayamo, 1991.

Gómez Báez Máximo, Diario de Campaña, Instituto del libro, La Habana, 1968.

Izaguirre, José María, Recuerdo de la Guerra de los Diez Años, (S.E.), (S.L.), (S.A.)

Jerez Villarreal, Juan, Gesta de Bravos. Episodios inéditos de la Revolución de 1968, Talleres tipográficos de cuba intelectual, La Habana, 1926.

Lacalle y Zauquest E. O, Cuatro siglos de historia de Bayamo. Proyecto Memoria, Bayamo. Ediciones Bayamo, 2010.

Maceo Verdecia, José, Bayamo, Editorial El Arte, Manzanillo, 1936.

Mari Aguilera, Idelmis, Bayamo en el último tercio del siglo XIX, Editorial Bayamo, Bayamo, 1999.

OKelly James, La Tierra del Mambí, Instituto del Libro, Habana, 1968.

Pirala, Antonio, Anales de la guerra de Cuba, (S.E.), Madrid, 1896.

Recibido: 20/10/2017

Evaluado: $15 / 11 / 2017$

Versión Final: 25/01/2018 